\title{
QUEEN'S
UNIVERSITY
BELFAST
}

\section{Rapid screening and multi-toxin profile confirmation of tetrodotoxins and analogues in human body fluids derived from a puffer fish poisoning incident in New Caledonia}

Rambla-Alegre, M., Leonardo, S., Barguil, Y., Flores, C., Caixach, J., Campbell, K., Elliott, C. T., Maillaud, C., Boundy, M. J., Harwood, D. T., Campàs, M., \& Diogène, J. (2018). Rapid screening and multi-toxin profile confirmation of tetrodotoxins and analogues in human body fluids derived from a puffer fish poisoning incident in New Caledonia. Food and Chemical Toxicology, 112, 188-193. [112]. https://doi.org/10.1016/j.fct.2017.12.039

Published in:

Food and Chemical Toxicology

Document Version:

Peer reviewed version

Queen's University Belfast - Research Portal:

Link to publication record in Queen's University Belfast Research Portal

\section{Publisher rights}

Copyright 2017 Elsevier.

This manuscript is distributed under a Creative Commons Attribution-NonCommercial-NoDerivs License

(https://creativecommons.org/licenses/by-nc-nd/4.0/), which permits distribution and reproduction for non-commercial purposes, provided the author and source are cited.

\section{General rights}

Copyright for the publications made accessible via the Queen's University Belfast Research Portal is retained by the author(s) and / or other copyright owners and it is a condition of accessing these publications that users recognise and abide by the legal requirements associated with these rights.

Take down policy

The Research Portal is Queen's institutional repository that provides access to Queen's research output. Every effort has been made to ensure that content in the Research Portal does not infringe any person's rights, or applicable UK laws. If you discover content in the

Research Portal that you believe breaches copyright or violates any law, please contact openaccess@qub.ac.uk. 


\section{Accepted Manuscript}

Rapid screening and multi-toxin profile confirmation of tetrodotoxins and analogues in human body fluids derived from a puffer fish poisoning incident in New Caledonia

Maria Rambla-Alegre, Sandra Leonardo, Yann Barguil, Cintia Flores, Josep Caixach, Katrina Campbell, Christopher T. Elliott, Claude Maillaud, Michael J. Boundy, D. Tim

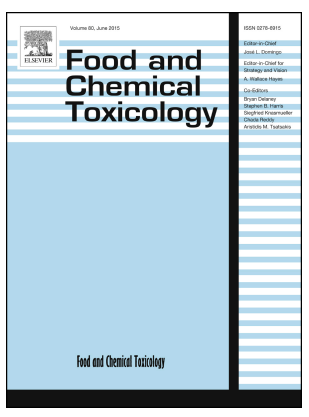
Harwood, Mònica Campàs, Jorge Diogène

PII: S0278-6915(17)30781-0

DOI: 10.1016/j.fct.2017.12.039

Reference: $\quad$ FCT 9484

To appear in: Food and Chemical Toxicology

Received Date: 8 October 2017

Revised Date: 11 November 2017

Accepted Date: 19 December 2017

Please cite this article as: Rambla-Alegre, M., Leonardo, S., Barguil, Y., Flores, C., Caixach, J., Campbell, K., Elliott, C.T., Maillaud, C., Boundy, M.J., Harwood, D.T., Campàs, Mò., Diogène, J., Rapid screening and multi-toxin profile confirmation of tetrodotoxins and analogues in human body fluids derived from a puffer fish poisoning incident in New Caledonia, Food and Chemical Toxicology (2018), doi: 10.1016/j.fct.2017.12.039.

This is a PDF file of an unedited manuscript that has been accepted for publication. As a service to our customers we are providing this early version of the manuscript. The manuscript will undergo copyediting, typesetting, and review of the resulting proof before it is published in its final form. Please note that during the production process errors may be discovered which could affect the content, and all legal disclaimers that apply to the journal pertain. 


\section{Rapid screening and multi-toxin profile confirmation of tetrodotoxins and analogues in human body fluids derived from a puffer fish poisoning incident in New Caledonia}

Maria Rambla-Alegre ${ }^{a}$, Sandra Leonardo ${ }^{a}$, Yann Barguil ${ }^{b}$, Cintia Flores ${ }^{c}$, Josep Caixach ${ }^{c}$, Katrina Campbell $^{d}$, Christopher T. Elliott ${ }^{d}$, Claude Maillaud ${ }^{e}$, Michael J. Boundy ${ }^{f}$, D. Tim Harwood ${ }^{f}$, Mònica Campàs ${ }^{a}$, Jorge Diogène ${ }^{a}$

aIRTA, Ctra, Poble Nou, km 5.5, 43540 Sant Carles de la Ràpita, Tarragona, Spain

${ }^{b}$ Service of Biochemistry, Territorial Hospital Center of New Caledonia, BP J5, 98849 Nouméa cedex, New Caledonia, France

${ }^{C}$ Mass Spectrometry Laboratory/Organic Pollutants, IDAEA-CSIC, Jordi Girona 18, 08034 Barcelona, Spain

'Institute for Global Food Security, School of Biological Sciences, Queen's University, Stranmillis Road, Belfast BT9 5AG, Northern Ireland

eLacave Laplagne Street, Noumea 98800, New Caledonia, France

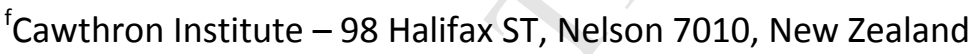

\section{Abstract}

In August 2014, a puffer fish poisoning incidence resulting in one fatality was reported in New Caledonia. Although tetrodotoxin (TTX) intoxication was established from the patients' signs and symptoms, the determination of TTX in the patient's urine, serum or plasma is essential to confirm the clinical diagnosis. To provide a simple cost-effective rapid screening tool for clinical analysis, a maleimide-based enzyme-linked immunosorbent assay (mELISA) adapted for the determination of TTX contents in human body fluids was assessed. The mELISA was applied to the analysis of urine samples from two patients and a response for the presence of TTX and/or 
structurally similar analogues was detected in all samples. The analysis by LC-MS/MS confirmed the presence of TTX but also TTX analogues (4-epiTTX, 4,9-anhydroTTX and 5,6,11trideoxyTTX) in the urine. A change in the multi-toxin profile in the urine based on time following consumption was observed. LC-MS/MS analysis of serum and plasma samples also revealed the presence of TTX $(32.9 \mathrm{ng} / \mathrm{mL})$ and 5,6,11-trideoxyTTX $(374.6 \mathrm{ng} / \mathrm{mL})$ in the postmortem plasma. The results provide for the first time the TTX multi-toxin profile of human samples from a puffer fish intoxication and clearly demonstrate the implication of TTX as the causative agent of the reported intoxication case.

Keywords: tetrodotoxin, urine, plasma, immunoassay, LC-MS/MS, puffer fish Corresponding author: Maria Rambla-Alegre (email: maria.rambla@irta.cat) 


\section{INTRODUCTION}

Tetrodotoxin (TTX) is one of the most potent low-molecular-weight marine neurotoxin, wellknown for its distribution in puffer fish, but also present in many other organisms, including amphibians, echinoderms, cephalopods and bivalve molluscs (Noguchi et al., 2008; Turner et al. 2017). It is believed to be primarily produced by certain marine endosymbiotic bacteria and to accumulate through the food webs and enter into other organisms, eventually reaching humans (Pratheepa and Vasconcelos, 2013). TTX and TTX analogues selectively bind to site one of voltage-gated sodium channels, blocking the influx of sodium ions into the nerve cells and affecting neuromuscular transmission, causing progressive paralysis and even death due to a failure of the respiratory system (Lee and Ruben, 2008).

Puffer fish food poisoning cases have been reported worldwide. A poisoning incidence reported by the Territorial Hospital of New Caledonia in August 2014 resulting from the ingestion of an Arothron nigropunctatus puffer fish (Maillaud et al., 2015) is addressed in this work to demonstrate the implication of TTX in this intoxication. At around $6 \mathrm{pm}$ on the $27^{\text {th }}$ of August, four men aged $33,34,37$ and 38 years old, with no known medical history, consumed a boiled fish that the oldest man had captured whilst fishing. The older fisherman ate most of the liver and the gonads in their totality. One of the other men consumed, the flesh in great quantity and, the other man consumed, a small portion of the liver. The fourth and youngest man only ingested a small part of the flesh. Rapidly, the first three consumers presented with gastrointestinal signs such as nausea, vomiting and diffuse abdominal pain, together with neurological signs such as peribuccal, facial and extremal paraesthesia and ataxia-like sensations. The three men lay down and fell asleep. On the morning of the $28^{\text {th }}$ of August, the fisherman was found deceased in his bed and the other two men showed regressed digestive signs and appearance of tetraparesis. The fourth consumer returned home with no signs of intoxication. The two men that presented with neurological signs were hospitalised, one patient in the intensive care unit (Pt\#1) and the other one (Pt\#2) in the short stay 
hospitalization unit of the Territorial Hospital of New Caledonia. The neurological symptoms with associating tetraparesis, tetraparesthesis, ataxia and deep sensitivity disturbance dissipated after 48 hours and disappeared in a few days.

Although the causative agent of the food poisoning was established from the patients' symptoms and the identification of the species responsible through the photos of the fish provided by the medical team to one of the patients, the puffer fish could not be analysed for the identification of the toxin involved in this intoxication case. Thus, the detection of TTXs in clinical samples of the poisoned patients can be essential to confirm TTX intoxication. As TTXs are very polar compounds, the ingested toxins are mainly eliminated in urine. Previous studies have indicated that TTXs only remain in blood for a matter of hours (less than $24 \mathrm{~h}$ ), but they can be found in urine even on day 4 after ingestion (O'Leary et al., 2004).

Chromatography-based methods have been to date the most widely used techniques for the determination of TTXs in the urine and blood of patients from poisoning incidents. However, determining TTX intoxication from body fluids faces certain challenges. First, unlike in food, the amount of toxin in the urine and blood of a patient who has been intoxicated is typically low; therefore, a sensitive method is required. Secondly, because TTXs are very polar compounds, there will be low retention on conventional reverse-phase columns; thus, the use of another type of analytical column or modification of the mobile phase composition is needed. Third, endogenous metabolites of the biological samples may lead to matrix effects. Ion suppression is a big challenge in mass spectrometry (MS) analysis, requiring efficient clean-up procedures before sample analysis (Leung et al., 2011).

Enzyme-linked immunosorbent assays (ELISAs) are rapid, sensitive, cost-efficient and easy-touse methods of analysis that do not require sophisticated instrumentation and highly trained personnel. The use of ELISAs as alternative or complementary to conventional methods for the determination of TTXs in biological samples can provide expedient solutions for rapid and reliable diagnosis in food poisoning incidences, and favours their implementation at hospitals 
where patients are treated. A maleimide-based ELISA (mELISA) for the detection of TTXs in mussels and oysters was recently developed at IRTA (Reverté et al., 2017). The TTX was immobilised on self-assembled cysteamine in a stable, ordered and optimally-oriented way that provided a long-term stability for storage of the modified microtiter plates, allowing the assay to be performed in less than 2 hours with the use of these pre-coated plates. To the best of our knowledge, only one work has used an immunoassay for the analysis of human body fluids for TTX monitoring, but no details are provided on the method or its performance (Islam et al., 2011). Here, the application of the mELISA to the screening of TTXs in clinical samples was assessed and fully characterised by the analysis of blank and TTX-spiked samples. Moreover, urine samples from the two intoxicated patients were analysed and the multi-toxin profile (TTX and TTX analogues) in urine, serum and plasma samples was evaluated by liquid chromatography-tandem mass spectrometry (LC-MS/MS) analysis. The results obtained by both techniques were compared, demonstrating the applicability of the immunoassay and the complementarity of the techniques based on different recognition principles.

\section{MATERIALS AND METHODS}

\subsection{Reagents and materials}

Pure TTX standard was purchased from Tocris Bioscience (Bristol, UK) and standard solutions were prepared at $1 \mathrm{mg} / \mathrm{mL}$ in $10 \mathrm{mM}$ acetic acid (AA). The anti-TTX monoclonal antibody (mAb) TX-7F was produced as described in Kawatsu et al. (1997). Pierce maleimide-activated plates were obtained from Thermo Fisher Scientific (Madrid, Spain). Cysteamine hydrochloride, formaldehyde solution, anti-mouse IgG (whole molecule)-horseradish peroxidase antibody produced in rabbit (IgG-HRP), bovine serum albumin (BSA), ethylenediaminetetraacetic acid (EDTA), 4-morpholineethanesulfonic acid (MES) hydrate, potassium phosphate dibasic, potassium phosphate monobasic and $3,3^{\prime}, 5,5^{\prime}-$ tetramethylbenzidine (TMB) liquid substrate, ammonium hydroxide solution $\left(\mathrm{NH}_{4} \mathrm{OH}, 25 \%\right)$, 
ammonium acetate and amorphous graphitized polymer carbon Supelco ENVI-Carb $250 \mathrm{mg} / 3 \mathrm{~mL}$ cartridges were supplied by Sigma-Aldrich (Tres Cantos, Spain). HPLC-grade acetonitrile (ACN), glacial acetic acid (AA) and methanol $(\mathrm{MeOH})$ were obtained from Chem-lab (Zedelgem, Belgium). Ultrapure Milli-Q water $\left(18.2 \mathrm{M} \Omega / \mathrm{cm}^{2}\right)$ was used for the preparation of solutions (Millipore Iberica Ltd., Madrid, Spain).

\subsection{Human samples}

Urine, serum and plasma samples were collected and stored at $-20^{\circ} \mathrm{C}$ until their analysis (Table 1). Urine and serum samples from patient $1(\mathrm{Pt} \# 1)$ were collected the $28^{\text {th }}$ and $29^{\text {th }}$ of August 2014, coinciding with $\sim 17 \mathrm{~h}$ and $\sim 45 \mathrm{~h}$ after the ingestion of the boiled puffer fish; urine and serum samples from patient 2 ( $\mathrm{Pt \# 2)}$ were taken only the second day of hospitalisation, approximately $42 \mathrm{~h}$ after the ingestion of the fish. Three plasma samples were collected from Pt\#1: the first one was collected at the moment of hospitalisation, $\sim 17 \mathrm{~h}$ after the puffer fish consumption; two additional samples were collected $\sim 38$ and $\sim 43 \mathrm{~h}$ after the ingestion; only one plasma sample was collected from Pt\#2, $\sim 23 \mathrm{~h}$ after the fish consumption. A post-mortem plasma sample was collected from the fisherman, $\sim 17 \mathrm{~h}$ after the puffer fish ingestion.

Table 1. Human body fluid samples collected from the two hospitalised patients and the deceased fisherman.

\begin{tabular}{|c|c|c|c|}
\hline & Date & $\begin{array}{c}\text { Time } \\
\text { (hours after } \\
\text { ingestion) }\end{array}$ & Samples \\
\hline \multirow{4}{*}{ Pt\#1 } & $28 / 08 / 14$ & $17 \mathrm{~h}$ & Urine, serum and heparinized plasma \\
\cline { 2 - 4 } & $29 / 08 / 14$ & $38 \mathrm{~h}$ & Heparinized plasma \\
\cline { 2 - 4 } & $29 / 08 / 14$ & $43 \mathrm{~h}$ & Heparinized plasma \\
\cline { 2 - 4 } & $29 / 08 / 14$ & $45 \mathrm{~h}$ & Urine and serum \\
\hline \multirow{2}{*}{ Pt\#2 } & $28 / 08 / 14$ & $23 \mathrm{~h}$ & Heparinized plasma \\
& $29 / 08 / 14$ & $42 \mathrm{~h}$ & Urine and serum \\
\hline
\end{tabular}




\begin{tabular}{|l|l|l|l|} 
Fisherman & $28 / 08 / 14$ & $17 \mathrm{~h}$ & Post-mortem plasma (with fluoride) \\
\hline
\end{tabular}

The creatinine concentration in urine samples was determined by Echevarne Laboratory (Barcelona, Spain) using Jaffe's reaction.

\subsection{Colorimetric maleimide-based enzyme-linked immunosorbent assay (mELISA)}

Urine samples were analysed by mELISA, using the protocol previously developed by our group for the determination of TTX in shellfish (Reverté et al., 2018). Briefly, $100 \mu \mathrm{L}$ of $1 \mathrm{mM}$ cysteamine in binding buffer (0.1 M potassium phosphate, $10 \mathrm{mM}$ EDTA, $\mathrm{pH} 7.2$ ) was added to the maleimide plates and incubated for $3 \mathrm{~h}$, followed by the direct immobilization of TTX ( 2 $\mu \mathrm{g} / \mathrm{mL}$ ) with formaldehyde (3.4\%) in the same buffer overnight. A competitive assay was then performed by incubating $50 \mu \mathrm{L}$ of free TTX/sample dilution and $50 \mu \mathrm{L}$ of 1:1,600 anti-TTX monoclonal antibody (mAb) dilution in 1\% BSA-phosphate buffer for 30 min. A blocking step was then performed with $200 \mu \mathrm{L}$ of $1 \%$ BSA-phosphate buffer for 30 min and, finally, $100 \mu \mathrm{L}$ of IgG- HRP at 1:1,000 dilution in 1\% BSA-phosphate buffer was incubated for $30 \mathrm{~min}$. The colorimetric response was measured at $620 \mathrm{~nm}$ after $10 \mathrm{~min}$ of TMB liquid substrate incubation.

\subsection{Solid-phase extraction (SPE) clean-up}

Solid-phase extraction (SPE) clean-up was used before LC-MS/MS analysis, adapting the protocol described by Boundy et al. (2015) for shellfish samples. In this work, the addition of $\mathrm{NH}_{4} \mathrm{OH}$ to the crude extract is avoided. Briefly, graphitized polymer carbon ENVI-carb cartridges were conditioned with $3 \mathrm{~mL}$ of $\mathrm{ACN} / \mathrm{H}_{2} \mathrm{O} / \mathrm{AA}(20: 80: 1$, v:v:v), followed by $3 \mathrm{~mL}$ of $\mathrm{H}_{2} \mathrm{O} / \mathrm{NH}_{4} \mathrm{OH}(1000: 1, \mathrm{v}: \mathrm{v})$. Then, $400 \mu \mathrm{L}$ of sample was loaded onto the conditioned cartridges and washed with $700 \mu \mathrm{L}$ of deionized $\mathrm{H}_{2} \mathrm{O}$. Finally, the retained TTXs were eluted with $2 \mathrm{~mL}$ of 
ACN/ $\mathrm{H}_{2} \mathrm{O} / \mathrm{AA}(20: 80: 1, \mathrm{v}: \mathrm{v}: \mathrm{v})$. The eluent was diluted by transferring $100 \mu \mathrm{L}$ to an insert and adding $100 \mu \mathrm{L}$ of $\mathrm{ACN}$. Sample vials could be stored at $-20^{\circ} \mathrm{C}$ until analysis.

\subsection{Liquid chromatography-tandem mass spectrometry (LC-MS/MS) analysis}

Urine, serum and plasma samples were analysed by LC-MS/MS, using the protocol previously developed by our group for the analysis of puffer fish (Rambla-Alegre et al., 2017). Briefly, a TSQ Quantum system (Thermo Fisher Scientific, Bremen, Germany) and a HILIC XBridge Amide column were used; a binary gradient elution was programmed with $\mathrm{H}_{2} \mathrm{O}$ (mobile phase A) and $\mathrm{ACN} / \mathrm{H}_{2} \mathrm{O}$ (mobile phase $\mathrm{B}$ ), both containing ammonium acetate and adjusted to $\mathrm{pH} 5.8$ with acetic acid. Extracts were analysed by electrospray ionisation (ESI) operating in positive mode, $[\mathrm{M}+\mathrm{H}]^{+}$; multiple reaction monitoring (MRM) transitions were monitored for the following TTX analogues (precursor ion > product ion): 320.1 > 302.1 / 162.2 for TTX and 4-epiTTX, 302.1 > 256.1 / 162.2 for 4,9-anhydroTTX, 304.1 > 286.1 / 162.2 for 5-deoxyTTX and 11-deoxyTTX, $288.1>270.1 / 224.0$ for 5,11-dideoxyTTX and 6,11-dideoxyTTX, $272.1>254.1 / 162.2$ for 5,6,11-trideoxyTTX, $290.1>272.1 / 162.2$ for 11-norTTX-6(S)-ol and 11-norTTX-6(R)-ol; identification was supported by the toxin retention time and MRM ion ratios. ESI parameters and voltages were optimised to: spray voltage of $3.5 \mathrm{kV}$, capillary temperature of $300{ }^{\circ} \mathrm{C}$, sheath gas flow rate of 40 (arbitrary units) and auxiliary gas flow rate of 10 (arbitrary units), capillary voltage of $30.0 \mathrm{~V}$, tube lens voltage of $130 \mathrm{~V}$ and skimmer voltage of $28 \mathrm{~V}$. Data was processed with Xcalibur 2.0.7 SP1 software (ThermoFisher Scientific, Bremen, Germany).

Quantification was calculated through an external calibration using TTX standard as a reference. Six level calibration curves between 1-250 ng/mL showed good intra-batch performance and linear adjustment $\left(r^{2}\right) \geq 0.9990$. According to the recoveries and dilution factor of the samples, the working ranges of the method in urine, plasma and serum were 12 $2,909 \mathrm{ng} / \mathrm{mL}, 25-6,361 \mathrm{ng} / \mathrm{mL}$ and $22-5,447 \mathrm{ng} / \mathrm{mL}$, respectively. 


\section{RESULTS AND DISCUSSION}

\subsection{Detection of TTX equivalent content in human samples by mELISA}

\subsubsection{Matrix effects and TTX recovery}

When performing an immunoassay, the functionality of the antibodies can be strongly affected by the presence of matrix compounds other than the target analyte, thus, the effect of each type of matrix on the assay should be evaluated prior to the analysis of naturally contaminated samples. To test urine matrix effects, pure and diluted blank and spiked ( $5 \mathrm{ng} / \mathrm{mL} \mathrm{TTX})$ urine samples were analysed. The mAb binding percentages obtained ranged between 95 and $104 \%$ for pure blank urine samples and all dilutions tested, indicating the lack of interference from urine matrix in the recognition of the immobilised TTX by the mAb. In contrast, urine matrix effects on the recognition of free TTX by the mAb were observed in the analysis of TTX-spiked urine samples, obtaining toxin recoveries of $27 \pm 4 \%$ in pure urine samples. Toxin recoveries increased with sample dilutions, reaching $101 \pm 2 \%$ recovery at $1 / 4$-diluted samples. Thus, it was clearly demonstrated that $1 / 4$ dilution of urine in buffer is an effective way to overcome matrix effects, avoiding sample pre-treatment. Considering $1 / 4$ urine dilution and the limit of detection (LOD) obtained in the standard calibration curve in buffer $\left(\mathrm{IC}_{10}=0.9 \mathrm{ng} / \mathrm{mL}\right)$, an effective LOD (eLOD) of $3.6 \mathrm{ng} \mathrm{TTX} / \mathrm{mL}$ urine was calculated, with a working range $\left(\mathrm{IC}_{20}-\mathrm{IC} \mathrm{C}_{80}\right)$ between 6.1 and $184.0 \mathrm{ng} \mathrm{TTX} / \mathrm{mL}$ urine. However, urine is a fluid with a large variation in matrix components and concentrations, differing both among people and within the same person depending on the status of dehydration of the patient. Thus, when the analysis is not compromised by analyte concentrations below the LOD, additional sample dilutions are encouraged to validate that the matrix effect has been completely removed and TTX equiv. content is not being underestimated.

In regards to the serum and plasma samples, the preliminary studies revealed high nonspecific absorption values from the secondary antibody in blank serum and plasma samples from pure samples to $1 / 8$ sample dilutions in binding buffer-. Due to the high interference of the 
matrix components in serum and plasma, the analysis of these clinical samples by mELISA was not fulfilled. Since mELISA is proposed as a rapid screening tool, the clean-up of serum and plasma samples to reduce the matrix effects was not approached. Determination of TTX in urine by mELISA is an appropriate strategy for clinical laboratory diagnosis due to the low matrix effects but also the long duration of TTX in urine compared with plasma and serum.

\subsubsection{Quantification of TTX equivalent content in urine samples}

Urine samples were analysed by mELISA to determine the TTX equiv. contents (Table 2). TTX equiv. were detected in all urine samples. To eliminate the effect of dehydration and variations in urinary output of the patients, urine creatinine adjustment of the TTX concentrations was made (Yu et al., 2010; Fong et al., 2011) expressing the concentration of TTX equiv. in relation to creatinine concentrations (ng TTX equiv./ $\mu$ mol creatinine). It was found that urine creatinine-adjusted TTX (UC-TTX) concentrations agree well with the degree of poisoning, as observed from clinical symptoms, and with the expected TTX excretion rates. In Pt\#1, the urine sample collected $\sim 17 \mathrm{~h}$ after fish ingestion presented the highest UC-TTX concentration. The UC-TTX content decreased in the urine sampled from the same patient $\sim 45 \mathrm{~h}$ after fish ingestion. Urine sample from Pt\#2, collected $\sim 42 \mathrm{~h}$ after fish ingestion, showed the lowest UCTTX levels. TTX equiv. contents found in urine are consistent with previous TTX intoxication episodes reported (Yu et al., 2010). However, in many cases the results are difficult to compare due to differences in the urine collection time and differences in the hydration state of patients and no adjustment with creatinine levels.

\subsection{Detection of TTXs in human samples by LC-MS/MS analysis}

\subsubsection{TTX recovery}

Urine, serum and plasma matrix effects were studied by the analysis of blank and TTX-spiked matrices. After SPE clean-up of the samples, toxin recoveries of $43 \%, 23 \%$ and $20 \%$ were 
obtained for urine, serum and plasma samples, respectively. The low recovery values achieved in the analysis of the clinical samples can be attributed to toxin loss during SPE clean-up and/or ion suppression. Nevertheless, these toxin recovery values are taken as correction factors (CFs) and will be applied in the quantifications obtained in the subsequent analysis of naturally contaminated samples extracted and treated under these conditions.

After applying the corresponding CFs, LODs of 5.9, 10.9 and $12.7 \mathrm{ng} \mathrm{TTX} / \mathrm{mL}$ and limits of quantification (LOQs) of 11.6, 21.8 and $25.4 \mathrm{ng} \mathrm{TTX} / \mathrm{mL}$ were calculated for urine, serum and plasma samples, respectively.

\subsubsection{Identification and quantification of $T \mathrm{XXs}$}

TTX content in urine, serum and plasma samples was evaluated by LC-MS/MS. As expected from the previous results obtained by mELISA, TTX was detected in all urine samples. Figure 1 shows the chromatograms obtained after the analysis of the urine sample of Pt\#2, as an example. The analysis revealed a multi-toxin profile in all urine samples, with the presence of TTX but also 4- epiTTX, 4,9-anhydroTTX and 5,6,11-trideoxyTTX analogues (Table 2, Figure 2). It is interesting to mention that whereas 5,6,11-trideoxyTTX was the major analogue found in urine from Pt\#1 collected $\sim 17 \mathrm{~h}$ after the puffer fish ingestion, TTX was the major compound found in urine from the same patient collected $\sim 45 \mathrm{~h}$ after the fish ingestion. Urine sample from Pt\#2, collected $\sim 42 \mathrm{~h}$ after the fish ingestion, also presented TTX as the major compound. Concentrations of TTX and TTX analogues obtained could suggest the metabolism of 5,6,11trideoxyTTX to TTX and its equivalent analogues 4-epiTTX and 4,9-anhydroTTX, a pathway already predicted by Yotsu-Yamashita et al. (2013). After adjusting TTX and TTX analogues values to creatinine concentration to correct the effect of dehydration and variations in urinary output, as performed in the quantifications by mELISA (section 3.1.2), a decrease of TTX and all the analogue concentrations was observed with time (hours after fish consumption). 
Consequently, the TTX metabolic pathway cannot be concluded from these results since differences in the metabolic profile could also be explained by the different stability of TTX analogues.

Figure 1.

Figure 2.

To obtain an estimation of the total TTX content of a sample in terms of toxicity (expressed in TTX equiv.), the application of the toxicity equivalency factors (TEFs) of each analogue to the individual quantifications provided by LC-MS/MS is necessary. TEFs express the toxicity of each individual analogue in relation to TTX toxicity used as a reference. Thus, TEFs for 4-epiTTX $\left(\mathrm{TEF}_{4-\text { ep } \pi T \mathrm{~T}}=0.156\right), 4,9$-anhydroTTX $\left(\mathrm{TEF}_{4,9-\text { anhydrotTx }}=0.019\right)$ and 5,6,11-trideoxyTTX $\left(\operatorname{TEF}_{5,6,11-}\right.$ trideoxy $\pi x=0.011$ ) previously established in the literature (Nakamura and Yasumoto 1985; YotsuYamashita et al. 1995) were applied to each $\Pi \mathrm{TX}$ analogue concentration in urine samples, obtaining TTX equiv. concentrations, which were afterwards adjusted according to creatinine concentrations. A correspondence between the adjusted values and the clinical symptoms of the patients was again observed.

Regarding serum and plasma samples from the hospitalised patients, neither TTX nor TTX analogues were detected above the LODs, which indicates the rapid elimination of TTX into urine. In contrast, TTX and 5,6,11-trideoxyTTX were detected in the post-mortem plasma sample from the fisherman at concentrations of $32.9 \mathrm{ng} / \mathrm{mL}$ and $374.6 \mathrm{ng} / \mathrm{mL}$, respectively (Figure 3). Although 5,6,11-trideoxyTTX was clearly the major compound detected in the plasma, its low toxicity compared with TTX points out TTX to be the main causative agent of this fatal case. It is important to take into consideration that blood TTX concentrations greater than $9 \mathrm{ng} / \mathrm{mL}$ have been suggested to be potentially lethal (Islam et al., 2011). The detection of TTX in the post-mortem plasma at this high concentration clearly reflects the high amount of 
TTX ingested by the fisherman, probably due to the consumption of liver and gonads, the most toxic parts of puffer fish species (Noguchi et al., 2008).

\section{Figure 3.}

\subsection{Comparison between TTX quantifications provided by mELISA and by LC-MS/MS analysis}

The application of cross-reactivity factors (CRFs) of TTX analogues to the individual contents determined by LC-MS/MS to obtain the total TTX content of a sample in terms of immunochemical recognition (expressed in TTX equiv.), is crucial when comparing results between immunochemical and physicochemical approaches. CRFs depend on the affinity of the antibody for the different analogues, but also on the immunological approach and the manner in which antibodies/antigens are immobilised (Reverté et al., 2015; Leonardo et al., 2017). CRFs for 4,9- anhydroTTX and 5,6,11-trideoxyTTX analogues were previously established by mELISA, being $10^{-4}$ and $10^{-6}$, respectively. Unfortunately, the CRF for 4-epiTTX could not be established due to the lack of standard. The total TTX equiv. content by LC-MS/MS was calculated by adding up the contents of TTX and TTX analogues after applying the corresponding CRFs to each analogue (Table 2). The low CRFs of 4,9-anhydroTTX and 5,6,11trideoxyTTX certainly makes the contribution of these analogues to the total sum to be very low. Since CRF for 4-epiTTX was not available, the CRF values of 0 and 1 were assumed for this analogue to provide a content range that should include the real values (this affects to samples from Pt\#1, as 4-epiTTX was not quantified in sample from Pt\#2). After creatinine adjustment, appropriate correlations between the C-TTX quantifications provided by mELISA and LCMS/MS analysis were obtained, regardless of whether 4-epiTTX CRF was considered to be 0

$\left(y=1.288 x-17.2, R^{2}=0.995\right)$ or $1\left(y=0.717 x-3.8, R^{2}=0.993\right)$. Due to the small amount of 4-epiTTX in relation to the total TTX content of the sample, no significant differences were observed either when the CRF applied was $0(t=0.405, p=0.706)$ or $1(t=0.813, p=0.462)$. 
Nevertheless, $p$-values obtained suggest that the real value should be closer to 0 , the affinity of the antibody to recognise 4-epiTTX in the mELISA probably being very low in comparison with TTX.

The interaction of toxins with antibodies is based on a structural recognition that is not necessary related to the toxicity. Ideally, an immunoassay should be able not only to recognise all toxic analogues that contribute to the intoxication case, but also to provide a quantification equivalent to the total toxicity. Thus, quantifications provided by mELISA were also compared with total TTX equiv. concentrations calculated after LC-MS/MS analysis. Good correlations were obtained $\left(y=1.050 x-11.5, R^{2}=0.990\right)$ with results showing no significant differences $(t=0.547, p=0.614)$. The lower affinity of the mAb towards less toxic TTX analogues in comparison with TTX makes the mELISA an ideal tool for preliminary screening of the toxicity of urine samples. Since only three urine samples were available in this study, additional samples should be analysed to fully validate this method. Nevertheless, the obtained results clearly demonstrate the applicability of the MELISA to both fast screening and quantification of TTX in urine samples in a simple and reliable way. 
Table 2. TTX and creatinine concentrations in urine samples of two patients with TTX poisoning and comparison between TTX quantifications provided by LC-MS/MS analysis and mELISA.

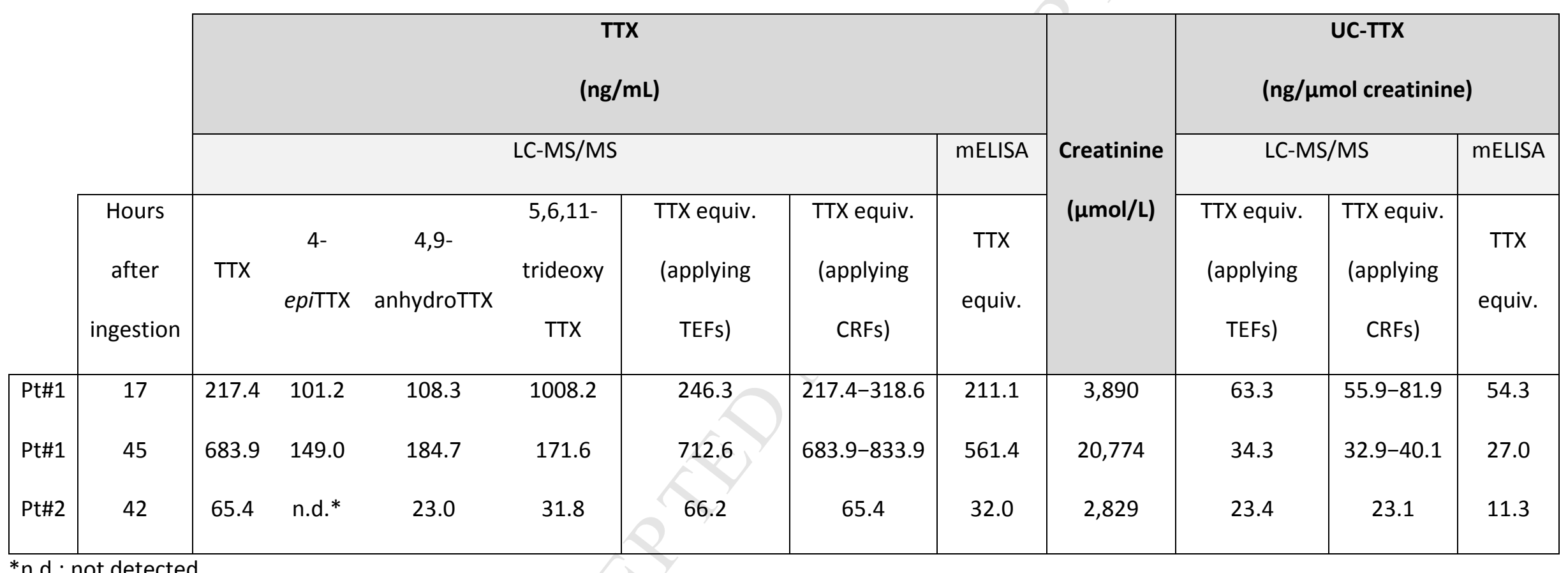




\section{CONCLUSIONS}

The implication of TTX as the responsible agent of the reported intoxication case in New Caledonia following consumption of puffer fish has been proven.

The applicability of the mELISA to the analysis of urine samples has been demonstrated, confirming the presence of TTX equiv. in all urine samples from the hospitalised patients. The results were in good correlation with LC-MS/MS analysis, that revealed a multi-toxin profile, with the presence of TTX and three TTX analogues (4-epiTTX, 4,9-anhydroTTX and 5,6,11trideoxyTTX). No TTXs were detected in plasma and serum of these patients by LC-MS/MS analysis, but TTX and 5,6,11-trideoxyTTX were detected in the post-mortem plasma of the fisherman at a lethal concentration of $37.0 \mathrm{ng} / \mathrm{mL}$, after applying the TEFs.

The results obtained herein show the mELISA as a powerful tool for the fast screening of TTXs in urine samples, surpassing some of the challenges associated with LC-MS/MS analysis (e.g. lack of retention on conventional reverse-phase columns or significant ion suppression due to endogenous substances in urine). The analysis of urine samples by mELISA is a reliable, simple and cost-effective strategy to estimate the degree of TTX poisoning in humans. The complementary analysis by LC-MS/MS performed in parallel confirms the causative intoxication agent and provide a full characterisation of the multi-toxin profile of the sample. This work constitutes the first report that describes the multi-toxin profile in urine and postmortem plasma samples after puffer fish consumption, and complements the previous information on TTX present in human samples.

The authors declare that there is no conflict of interests regarding the publication of this paper. 


\section{Acknowledgments}

The research leading to these results has received funding from the the Instituto Nacional de Investigación y Tecnología Agraria y Alimentaria (INIA) through the PROMAQUA project (RTA2013-00096-00-00) and from CERCA/Generalitat de Catalunya program. Sandra Leonardo acknowledges scholarship from IRTA-Universitat Rovira i Virgili-Banco Santander (2013PIPF URV-IRTA-BS-01).

\section{References}

Boundy M.J., Selwood A.I., Harwood D.T., McNabb P.S., Turner A.D., 2015. Development of a sensitive and selective liquid chromatography-mass spectrometry method for high throughput analysis of paralytic shellfish toxins using graphitised carbon solid phase extraction. J. Chromatogr. A 1387, 1-12.

Fong B. M.-W., Tam S., Tsui K.-H., Leung S.-Y. K., 2011. Development and validation of a highthroughput double solid phase extraction-liquid chromatography-tandem mass spectrometry for the determination of tetrodotoxin in human urine and plasma. Talanta 83, 1030-1036.

Islam Q.T., Razzak M.A., Islam M.A., Bari M.I., Basher A., Chowdhury F.R., Sayeduzzaman A.B.M., Ahasan H.A.M.N., Faiz M.A., Arakawa O., Yotsu-Yamashita M., Kuch U., Mebs D., 2011. Puffer fish poisoning in Bangladesh: clinical and toxicological results from large outbreaks in 2008. Trans. R. Soc. Trop. Med. Hyg. 105, 74-80.

Kawatsu K., Hamano Y., Yoda T., Terano Y., Shibata T., 1997. Rapid and highly sensitive enzyme immunoassay for quantitative determination of tetrodotoxin, Jpn. J. Med. Sci. Biol. 50, 133150.

Lee C.H., Ruben P.C., 2008. Interaction between voltage-gated sodium channels and the neurotoxin, tetrodotoxin. Channels 2, 407e412. 
Leonardo S., Rambla M., Samdal I.A., Miles C.O., Kilcoyne J., Diogène J., O'Sullivan C.K., Campàs M., 2017. Immunorecognition magnetic supports for the development of an electrochemical immunoassay for azaspiracid detection in mussels. Biosens. Bioelectron. 97, 200-206

Leung K. S.-Y., Fong M.-W. B., Tsoi Y.-K., 2011. Analytical challenges: Determination of tetrodotoxin in human urine and plasma by LC-MS/MS. Mar. Drugs 9, 2291-2303.

Nakamura M., Yasumoto T., 1985. Tetrodotoxin derivatives in puffer fish. Toxicon 23, 271-279.

Noguchi T., Arakawa O., 2008. Tetrodotoxin - Distribution and accumulation in aquatic organisms, and cases of human intoxication. Mar. Drugs 6, 220-242.

O'Leary M.A., Schneider J.J., Isbister G.K., 2004. Use of high performance liquid chromatography to measure tetrodotoxin in serum and urine of poisoned patients. Toxicon 44 , 549-553.

Pratheepa V., Vasconcelos V., 2013. Microbial diversity associated with tetrodotoxin production in marine organisms. Environ. Toxicol. Pharm. 36, 1046-1054.

Maillaud C., Barguil Y., Le Coq Saint-Gilles H., Mikulski M., Guittonneau-Leroy A.L., Pérès H., Nour M., 2015. Puffer fish poisoning in New Caledonia. Case reports. Toxicologie Analytique et Clinique 28, 57-63.

Rambla-Alegre M., Reverté L., del Río V., de la Iglesia P., Palacios O., Flores C., Caixach J., Campbell K., Elliott C.T., Izquierdo-Muñoz A., Campàs M., Diogène J., 2017. Evaluation of tetrodotoxins in puffer fish caught along the Mediterranean coast of Spain. Toxin profile of Lagocephalus sceleratus. Environ. Res. 158, 1-6.

Reverté L., de la Iglesia P., del Río V., Campbell K., Elliott C.T., Kawatsu K., Katikou P., Diogène J., Campàs M., 2015. Detection of tetrodotoxins in puffer fish by a self-assembled monolayerbased immunoassay and comparison with surface plasmon resonance, LC-MS/MS and mouse bioassay. Anal. Chem. 87, 10839-10847.

Reverté L., Rambla-Alegre M., Leonardo S., Bellés C., Campbell K., Elliott C.T., Gerssen A., Klijnstra M.D., Diogène J., Campàs M., 2018. Development and validation of a maleimide-based 
enzyme-linked immunosorbent assay for the detection of tetrodotoxins in oysters and mussels. Talanta 176, 659-666.

Turner A.D., Boundy M.J., Dhanji Rapkova M, 2017. Development and single-laboratory validation of a liquid chromatography tandem mass spectrometry method for quantitation of tetrodotoxin in mussels and oysters. JAOAC Int. 100 (5) 1-14.

Yotsu-Yamashita M., Abe Y., Kudo Y., Ritson-Williams R., Paul V.J., Konoki K., Cho Y., Adachi M., Imazu T., Nishikawa T., Isobe M., 2013. First identification of 5,11-dideoxytetrodotoxin in marine animals, and characterization of major fragment ions of tetrodotoxin and its analogs by high resolution ESI-MS/MS. Mar. Drugs 11, 2799-2813.

Yotsu-Yamashita M., Yamagishi Y., Yasumoto T., 1995. 5,6,11-Trideoxytetrodotoxin from the puffer fish, Fugu poecilonotus. Tetrahedron Lett. 36, 9329-9332.

Yu C.H., Yu C.F., Tam S., Yu P.H.F., 2010. Rapid screening of tetrodotoxin in urine and plasma of patients with puffer fish poisoning by HPLC with creatinine correction. Food Addit. Contam. 27, 89-96. 


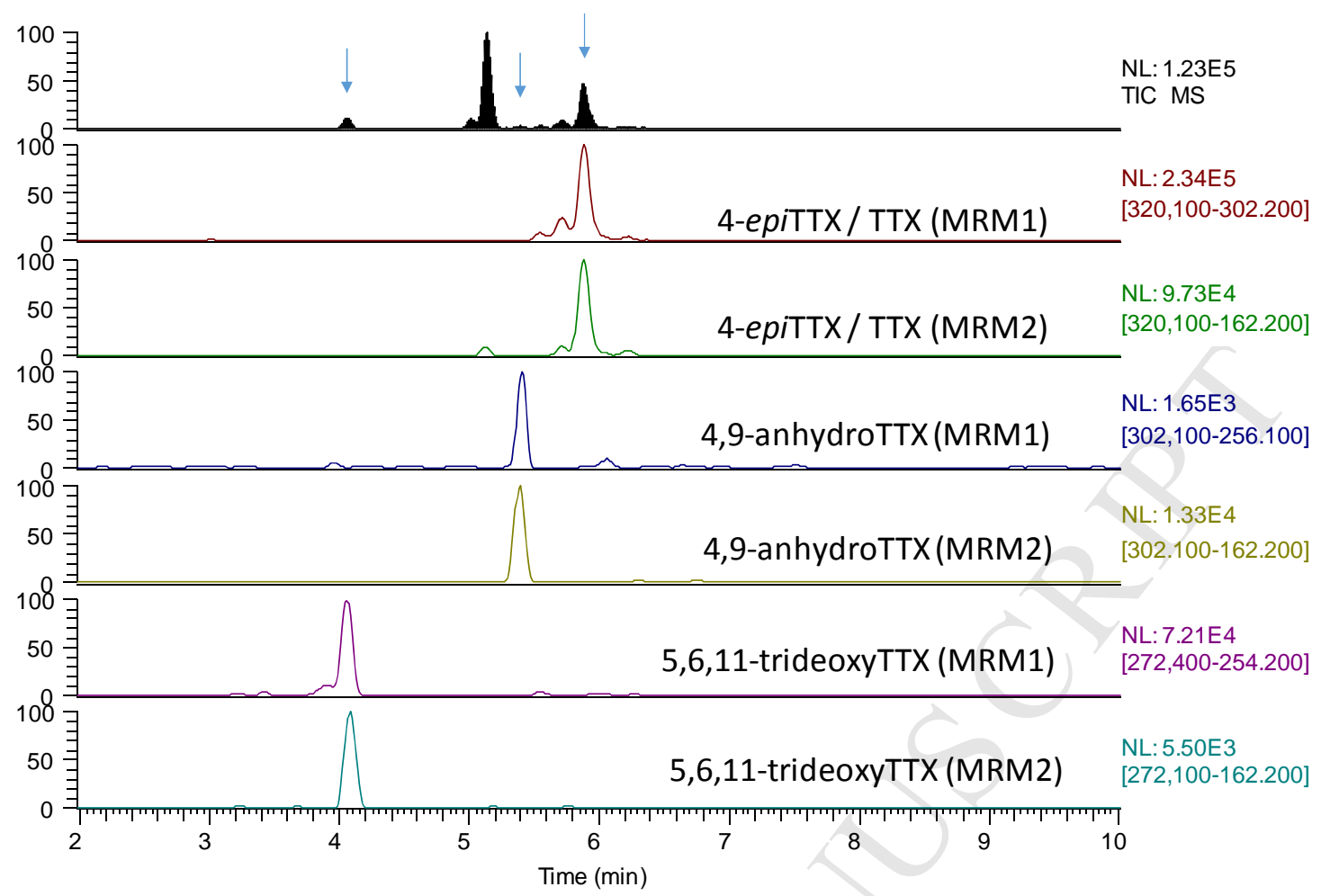

Figure 1. Total ion chromatogram (TIC) and MRM chromatogram of transitions monitored obtained following the analysis of TTX and its analogues in urine from Pt\#2 by LC-MS/MS. Arrows indicate TTX and TTX analogues peaks identified. 


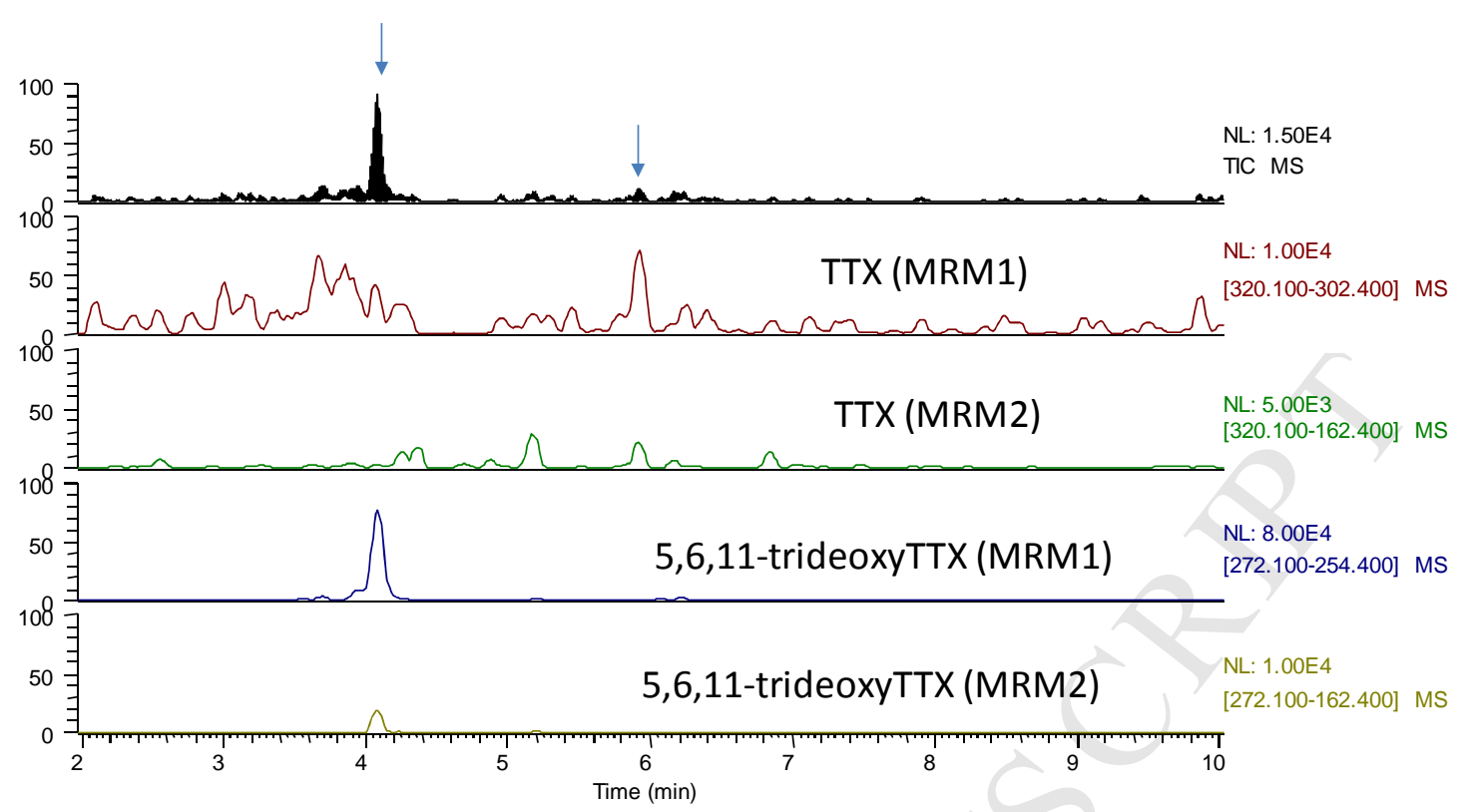

Figure 3. TIC and MRM chromatogram of transitions monitored obtained following the analysis of TTX and its analogues in post-mortem plasma from the fisherman by LC-MS/MS. Arrows indicate TTX and TTX analogues peaks identified. 
Pt\#1

$\sim 17 \mathrm{~h}$ after ingestion

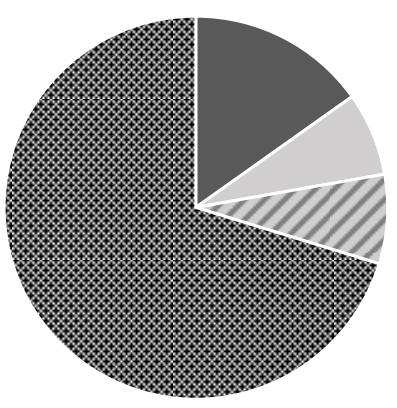

Pt\#1

$\sim 45 \mathrm{~h}$ after ingestion

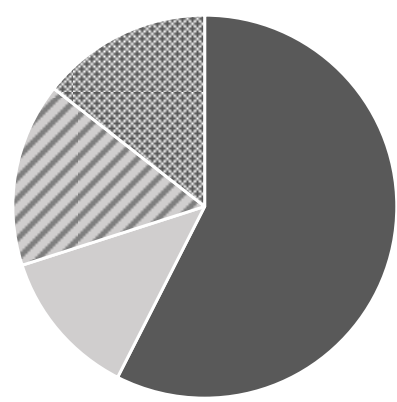

Pt\#2

$\sim 42 \mathrm{~h}$ after ingestion

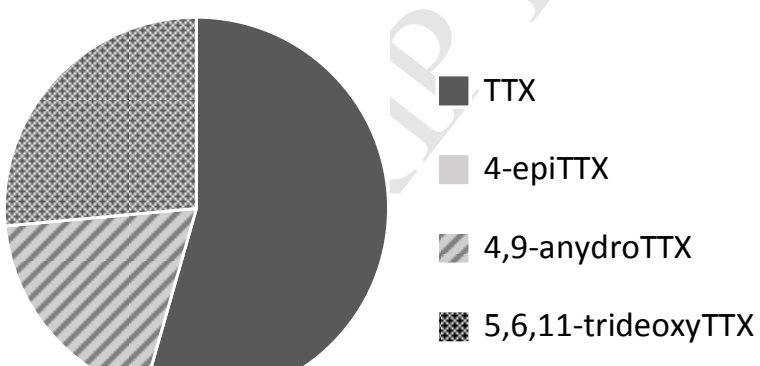

Figure 2. Graphical representation of the multi-toxin profile of the urine samples. 
Pt\#1

$\sim 17 \mathrm{~h}$ after ingestion

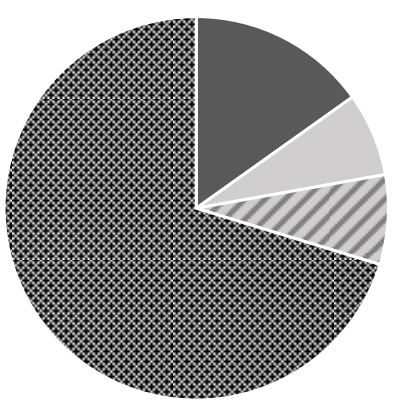

Pt\#1

$\sim 45 \mathrm{~h}$ after ingestion

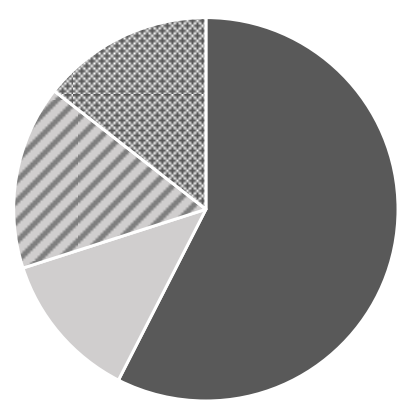

Pt\#2

$\sim 42 \mathrm{~h}$ after ingestion

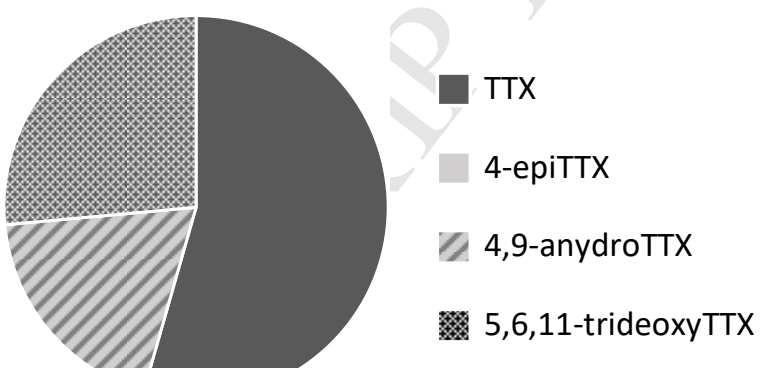

Figure 2. Graphical representation of the multi-toxin profile of the urine samples. 


\section{Highlights}

- First report that describes the TTX multi-toxin profile in urine and post-mortem plasma after puffer fish consumption.

- A user-friendly screening and quantification analysis tool for TTX in urine samples is provided.

- Excellent correlation of LC-MS/MS and mELISA is obtained in the analysis of urine samples.

- A change in the TTX multi-toxin profile in the urine based on time following consumption is observed.

- Analysis of urine and plasma confirmed the presence of TTXs and demonstrates their implication in the intoxication. 